\title{
Building trust and confidence through sustainable information systems research: towards a common future
}

\author{
Karen Anderson \\ Department of Archives and Computer Science \\ Mid Sweden University \\ Universitetsbacken 1, 871-88 Härnösand, Sweden \\ Karen.Anderson@miun.se
}

\section{Summary}

The Information Systems research group at Mid Sweden University is the result of four separate groups, spread across three disciplines, artificially thrown together because we didn't seem to fit into other developed research groups. What we were seen to have in common was 'information'. The disciplines are: Archives and Information Science, Business Management and Organization, and Informatics.

Shortly after this uncertain start, the University launched a demanding internal process for Assessment of Research and Coproduction (ARC13) over the previous five years. We didn't have that much past together, so we set out to build ourselves a future, exploring our common interests as we gathered data for the evaluation. We pooled our research, hired a facilitator to help with a SWOT analysis, built trust within the group and achieved a remarkably good report from the external assessors. Participation in the multidisciplinary InterPARES Trust in Digital Records in an Increasingly Networked World Project has been an inspiring factor in the Archives and Information Science contribution to our new collaboration. Our Information Systems research group now focuses on five research challenges: Information value, quality, accessibility, sustainability and trustworthiness. Now we are having fun exploring the possibilities, confident that our InfoSys research group has its own sustainable future.

Keywords: sustainable information, information systems, social sustainability, archival science, trust, recordkeeping informatics

\section{Introduction}

Founding a research group is never an easy undertaking. It needs a group of likeminded, well-qualified researchers with similar or complementary interests. They should be willing, and preferably very keen to work together. Within a university, this encompasses not only the research they want to do, but also participation in the administration of the research group, and promotion of its interests within the life of the university. Successful researchers also teach from their 
research, which in turn requires cooperation and coordination to review and continually update existing teaching programmes, or development of new courses and programmes. In order to be successful in these endeavours, research groups need to build a trusting environment in which to work and through that environment develop confidence in their own standing and ability to weather the challenges that they meet.

\section{Purpose}

The purpose of this paper is to share the experience of four small research groups within Mid Sweden University who became one, the InfoSys research group. It will reflect on why our melding was seen to be necessary and how the group has worked together to achieve our successes so far, identifying a theoretical ground that can frame both our teaching and research.

\section{The background and our challenge}

In 2010 three independent, discipline-based groups were challenged to combine to become one new research group by the then head of the Institute for Information Technology and Media (ITM) at Mid Sweden University. The groups were Archives and Information Science, Informatics, and Business Management and Organization. The reasoning was that all three were very much smaller than other, longer-established research groups within ITM, such that none were deemed to have sufficient critical mass to succeed alone and that all had a common interest in 'information'. Until this point each group had worked hard and made a sound start to developing their own cohesive research focus so this decision came as something of a shock. To add to the challenge, the three groups were geographically separate, spread across three campuses in the middle of Sweden: Härnösand, Sundsvall and Östersund.

\section{The foundational groups}

The disciplines within which the research groups had developed were:

- Archives and Information Science at the Härnösand campus, which in 2009 had formed the CEDIF research group - the Centre for Digital Information Management, bringing together professional and research expertise in recordkeeping (archives and records management), business process analysis, systems design, information architecture, and long-term digital preservation.

- Informatics at the Östersund campus had formed the CRIINFO research group - Critical Information. CRIINFO focused on design of systems for accessibility of critical information undertaking applied research in close cooperation with stakeholders in order to create benefit.

- Business Management and Organization at the Sundsvall campus at that stage was a single research group known as VallT (Value creation with 
IT). ValIT focused on how value is translated, enacted and performed in IT-related processes and evaluation of these processes. At this stage they were still a single group, but by 2013 ValIT had defined their interests into two separate groups: CRIDIT - Critical Studies in Digital Information Technology and CIE - Computational Industrial Engineering.

Each of the partner groups had a unique position in a small and specialized niche: we had to start by getting to know each other and our various specializations. We instituted a series of monthly seminars, presenting two papers at each seminar, nominating two critical readers for each paper and circulating the chair. The university's videoconference facilities were used to ensure that as many as possible could participate. We also initiated a series of less frequent face-to-face meetings with the aim of trying to build a common identity, the first being held in October 2010, where we agreed on a name for the group that covered our common interests: Sustainable Information and Information Systems (SIIS). Since then we have held regular bi-annual meetings, which have become crucial to our development.

At this time ITM was in the process of developing a research strategy, a vision that could be presented to the public and research funding organizations and a development plan for our own measurable goals for evaluation purposes. Although its constituent campuses each had a considerably longer history, Mid Sweden University is celebrating 10 years as a university in 2015, so we were participating in building both ITM's and the new university's research identity. By the end of January 2011, we had our own vision statement:

We shall be acknowledged and leading within sustainable information and information systems (SIIS). This will be achieved through innovative multi-disciplinary research which creates new perspectives and values. We use our double affiliation as both technologists and social scientists to nuance and challenge taken for granted ways of understanding information and information technologies, their development and use. We view technologies not only as separate artifacts but as contexts of information, people, technology, design, manufacturing and use, organizations and use practices. We also focus on how technologies achieve value and meaning in various use contexts, and contribute to conditions for sustainable ways of living and working for people, organizations and communities.

This statement was extrapolated into a position statement paper (Truex et al 2011), in which we made some first steps towards defining our understanding of the relation between the information systems field and the notion of sustainability. However, several members of the group expressed a need for caution, concerned that it was too early and we had not had time for each group to thoroughly explore the issues from their own perspectives before attempting to 
write together. Nevertheless, we decided to go ahead and submit the paper as a first step towards developing our vision and stance.

From CEDIF's perspective, sustainability is central to archival and information science. In this field sustainable information is about recorded information (records) that can maintain authenticity, reliability, integrity, and still be usable over a long time, possibly forever. The records of road and rail transport systems provide an important example, for which maintenance of accurate accessible records is extremely important for the safety of future generations and the infrastructure bequeathed to them. Embedded in archival theory is the need to preserve the record for both current need and future use, underpinning business needs and an open and democratic society, which makes the social sustainability (e.g. McKenzie, 2004) construct relevant. The design of information systems in which records are created and managed are a particular challenge for sustainability: few information systems are designed to support the long-term preservation and accessibility of records. Indeed, Upward et al (2014, pp.38-39) describe the discipline as being in crisis and in crucial need of a re-think to develop what they call "a single-minded approach".

\section{Building trust and confidence}

Writing that first paper for the IFIP International Working Conference was strongly advocated in good faith, but in hindsight it was not well timed. It served best to make us realize that we had a lot more work to do to fully understand the potential contributions and standpoints of all our component subgroups. However, at the time, we simply did not have the maturity as a group and the confidence to decline the offer.

Shortly after this uncertain start, the University launched a demanding internal process for Assessment of Research and Coproduction (ARC13) over the previous five years. We didn't have that much past together, so we set out to build ourselves a future, exploring our common interests as we gathered data for the evaluation. We pooled the research we had done as individual groups and hired a facilitator to help with a SWOT analysis, which was a required part of the process. Working together on a frank analysis, starting with the strengths and weaknesses of the individual groups and then moving on to what we saw as the strengths and weakness of the combined group proved crucial to building trust within the group. It also helped us to identify common interests and most importantly, what we saw as shared challenges, and thus a way forward for tackling those challenges. When the assessment report was published in late 2014, we were very proud to have achieved an overall assessment of 'Very Good' from the panel of international assessors - the second highest on a 5-step grading scale. The report by the international Evaluation Panel commended our achievements in the areas of quality, productivity, co-production including external non-academic productivity, and impact on society (ARC13 2014, pp. 213-220). They also gave constructive advice and encouragement to continue 
the strategic planning begun while working towards this evaluation and to consolidate and stabilize achievements (p.219). This was a very helpful factor in building our confidence in our own achievements and standing within the university. An important recommendation was to establish a clear leadership structure for the group. Planning our work to meet the requirements of the $\mathrm{ARC} 13$ process and writing the self-assessment for presentation to the Evaluation Panel had been entrusted to a group of three to ensure fair representation of all three of out component groups and all three campuses. The group consisted of Karen Anderson (Professor in Archives and Information Science), Katarina Lindblad-Gidlund (Associate Professor in Business Management and Organization) and Lena-Maria Öberg (Senior Lecturer in Informatics). At a meeting in 2014 the InfoSys Group discussed leadership possibilities and voted to maintain and confirm this representative leadership model. The advantage of this leadership troika is that it has good access and support across the whole group, which in turn facilitates not only leadership but also the group's capacity to implement and deliver upon agreed decisions.

\section{Challenges facing the Information Professions}

The digital turn in society brings both opportunities and problems. Information technology has made e-service and e-business development possible but raises also problems relating to democracy, the leadership of these new processes and new roles and working methods. In 2010-11 the CEDIF group undertook a project to benchmark information management practice in Sweden, using a webbased survey, focus groups and interviews (Anderson, Samuelsson \& Morner Jansson, 2011). In one of the focus groups we conducted, information architects from large government departments noted the following competence deficits as being among the greatest challenges:

- Lack of relevant competence to create information and concept models in order to secure the quality in the information structures;

- Lack of relevant competence for work with enterprise business information modelling;

- Lack of alignment among different competencies and roles within the information management area leaves gaps and deficits in necessary competency levels.

Some archivists who were interviewed at the same time expressed a need for more knowledge and skills in the IT arena to enable them to better understand and participate in digital information management, particularly noting a lack of competence in enterprise-wide information modeling and development of strategies for ensuring quality in information structures, systems development and business process development. The survey also found that there was a lack of understanding of the complexity of managing information over the long-term, often because the focus was on IT solutions and under-using the professional 
knowledge of the archivist. It is encouraging to note that there are now an increasing number of calls in Sweden for sustainable IT design. In our 2010 survey we asked specific questions about this, but found that at that time there was little action or awareness of sustainability issues in the field of information management.

Beginning in 2011 the National Archives of Sweden worked on a very large project (the e-ARD Project) to design and implement a set of common specifications for government agencies that would facilitate and standardise transfer of records to an e-archive. Although the project was successfully completed in 2014, it became clear as it progressed that there are very few archivists in Sweden who have sufficient competence to either design or to implement such standards in their organisations. Disturbingly, the National Archives does not have sufficient resources to provide training that will ensure implementation of the specifications across all public organizations.

In the Swedish job market, there are an increasing number of positions for socalled "IT-archivists", signalling employers' requirements for archivists capable of working with IT professionals and who have the appropriate competence to design, implement and maintain systems that capture and manage records and their flow into the archive, ensuring long-term preservation. It is also an indicator of increasing frustration with the lack of general technological competence among those who currently work as archivists, while information governance, quality recordkeeping strategies for current business, retrieval and re-use, the needs, opportunities and threats presented by our digital society receive less attention than preservation strategies. This should be a matter of deep concern for the profession, given that this leaves an opening for other professions to move into archivists' professional arena, a problem identified by Maria Kallberg in her research. Having identified a lack of recordkeeping awareness in both the political and managerial arenas, she noted: "As researchers within the field of archival science we should strive to communicate our results with other research communities, such as the information system technology field. Research findings indicate that IT professions are increasing their professional positions and influence within the strategic e-government work. ... There is still a core of knowledge that is exclusive for this field ... [that] needs to be nourished and explored in order to find new models, but furthermore, acknowledge and secure the societal function of archives in a broader perspective, as sources to serve the whole society and not only to serve organisations' business needs" (Kallberg 2013, pp. 123-4).

Reflecting on these issues we saw that education for information professionals needs a major overhaul. Our vision can be compared to that of Oliver et al (2009; 2010), who pointed out that records and archives management faces an imminent crisis and argued for an overhaul of the discipline, proposing what they call "recordkeeping informatics" and urging active engagement in reshaping and broadening philosophy and approach (2009a, p.18). They advocate 
- Exploration of the technical and social environments facing organisations and their risk-related responses;

- Undertaking business analysis to understand the information architectures that intersect in sustainable ways with the enterprise architectures;

- Flexible and responsive frameworks to facilitate access to and rendering of authentic records and information in a secure and trustworthy manner;

- Understanding the information culture within organisations;

- Embracing a service oriented approach (Oliver et al 2010).

Furthermore, the InfoSys Groups shared research seminars also prompted us to begin exploring the issue of sustainability in the digital information society. Sustainability is usually seen as having three dimensions: environmental, economic and social. All are important, but it is the social aspects of sustainability that mesh best with our disciplinary interests. Yet Cuthill (2010, p. 363) notes that although there has been some exploration of concepts surroundling social sustainability, there does not appear to have been a broader academic response. Cuthill proposes a social sustainability framework "which describes an interdependent and self-reinforcing relationship between four key components: (1) social capital, (2) social infrastructure, (3) social justice and equity and (4) engaged governance".

Sustainable information systems and strategies for provision of sustainable information, i.e. information that is authentic, reliable and accessible over the long term, contributes to and underpins all four of Cuthill's components. Sound information governance and infrastructure, for example, are essential for supporting social justice and equity in a democratic society.

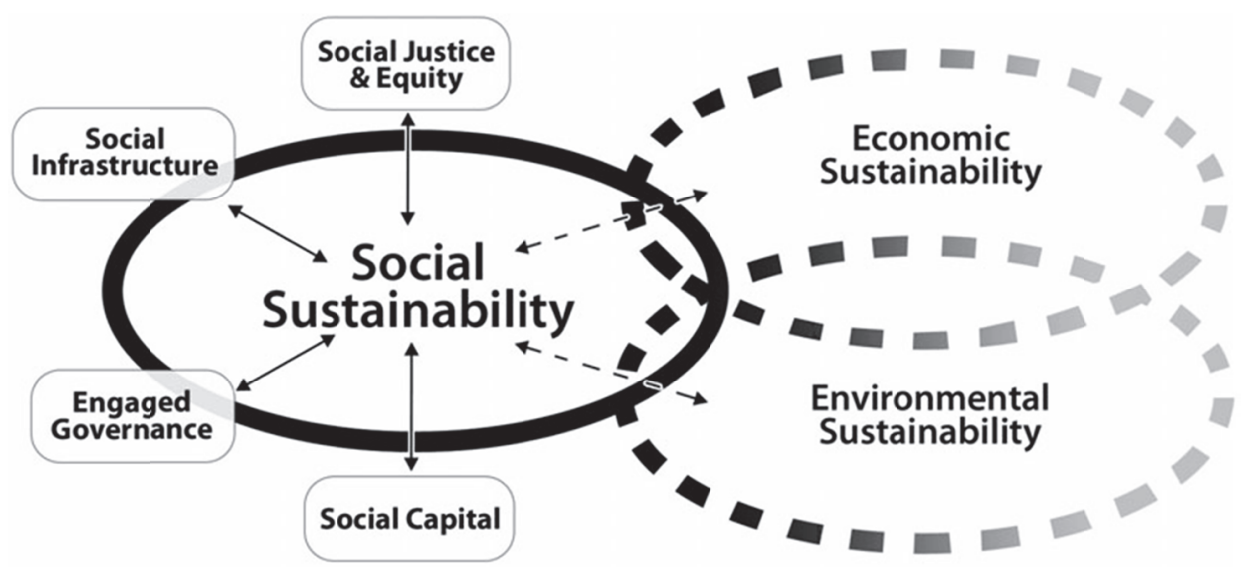

Figure 1: Conceptual framework for social sustainability (Cuthill 2010, p. 366) 


\section{Common ground}

At a meeting in April 2015 the InfoSys Group affirmed five key research challenges: Information value, quality, accessibility, sustainability and trustworthiness. Each of our constituent groups presented their own theoretical and discipline-focused strategies for subscribing to these five challenges and archives and information science found no difficulty in matching them to our past and present research and teaching. As well as supporting the objectives of our regionally funded research projects, these key challenges also reflect the objectives of the multidisciplinary, international InterPARES Trust in Digital Records in an Increasingly Networked World Project, membership of which has been an inspiring factor in the CEDIF Group's contribution to our InfoSys collaboration. The InterPARES Trust Project's research goal focuses on conditions and strategies for ensuring public trust in digital records entrusted to the Internet grounded on evidence of good governance, a strong digital economy, and a persistent digital memory ${ }^{1}$. Thus we draw on our international research partnership as well as the combined academic disciplines assembled within the InfoSys group, well-placed to explore and research the relationship between social sustainability and sustainable information, and to educate professionals who will be capable of meeting these challenges.

\section{A new Master degree in Sustainable Information Provision}

All three of the discipline groups who are partners in the InfoSys group teach at undergraduate level, and all offer research education at doctoral level, but currently only Archives and Information Science offers a master program, which was identified as a structural problem in our education program. Better coverage of our disciplinary interests at master level is needed for several reasons. Our research and shared experience between 2010 and 2014 made us increasingly aware of a need for a new approach to master level education across our disciplines to provide graduates with the knowledge and competences urgently required in our increasingly networked information environment. We are committed to ensuring that our research should always have a strong connection to our education programs at all levels, since we see informing our teaching through our research as one of our most important tasks. And to complete the circle, we need to create a new pool of Master degree graduates who will be particularly well-qualified to research with us as doctoral candidates in the future.

This led us to propose a new Master degree in Sustainable Information Provision, with a special focus on management and design of information services, for which the first student intake will be in 2016. Students will graduate with one of three specialisations, however eight of the courses in the two-year pro-

\footnotetext{
${ }^{1}$ InterPARES Trust https://interparestrust.org (Accessed 12 October 2015)
} 
gram will be common to all three streams. Of these, three are existing archival science courses covering Archival Theory, Information and Records Management and Current Issues in Archival Research. Three more will be new, jointly developed courses: Sustainable Information, Sustainable Architecture, and Design and Use of Information Systems. Courses contributed by the Informatics and the Business Management and Organization disciplines include Business Process Analysis, Change Management, Knowledge Management in Distributed Environments, Organisational Culture and Change, and Information Sharing. There will also be one project course in which students will work in groups comprising representatives of each specialisation, making nine common courses in all. In their final semester students will write a thesis oriented to their specialisation.

Our aim is to provide students with a deeper knowledge of information management that is fit for purpose in the evolving digital society. Students will also gain skills for managing projects across distributed work environments: essential for leading and designing information management solutions that are sustainable for multiple audiences and for achieving sustainable information over time. This will require specific knowledge of methods based on inclusive, democratic and participative principles.

\section{Conclusion}

The InfoSys Research Group's strategy of maintaining the identity and honouring the knowledge and expertise of each of our component subgroups, at the same time as we knit ourselves together has paid dividends. We have determined that strategic cooperative development will provide our best opportunities for future development of shared research and education, trusting and honouring the value that each discipline brings to the others rather than attempting to homogenise ourselves and water down our expertise to the lowest common denominator. In doing so, we believe we can make a real contribution to the future sustainability of our research group, to educating for sustainable information provision and in so doing, supporting a sustainable digital society.

\section{Acknowledgements}

I would like to thank my colleagues in the InfoSys group, particularly Katarina Lindblad-Gidlund and Lena-Maria Öberg. Working with them is always uplifting and they have provided the inspiration for this paper. 


\section{References}

Anderson, Karen; Samuelsson, Göran; Morner Jansson, Marie. Benchmarking Information Management Practice and Competence in Swedish Organizations. $/ / 5^{\text {th }}$ European Conference on Information Management and Evaluation. University of Insubria, Como, Italy. 8-9 September, 2011

ARC13: Assessment of Research and Coproduction at Mid Sweden University 2013. Sundsvall, Mid Sweden University: 2014. ISBN 978-91-87557-72-9 http://www.miun.se/siteassets/forskning/arc13/arc_bok_web_20140613.pdf

Cuthill, Michael. Strengthening the 'Social' in Sustainable Development: Developing a Conceptual Framework for Social Sustainability in a Rapid Urban Growth Region in Australia. Sustainable Development. 18, (2010). 362-373

Evans, Joanne; Reed, Barbara; Linger, Henry; Goss, Simon; Holmes, David; Drobik, Jan; Woodyat, Bruce; Henbest, Simon. Winds of Change. // Records Management Journal. Vol. 24 (2014), Iss 3; 205 - 223 http://dx.doi.org/10.1108/RMJ-01-2014-0006

Kallberg, Maria. 'The Emperor's New Clothes' Recordkeeping in a New Context. Doctoral Thesis. Sundsvall, Mid Sweden University (2013). ISBN 978-91-87557-21-7

McKenzie, Stephen. Social Sustainability: Towards Some Definitions. Magill, South Australia: Hawke Research Institute, University of South Australia: 2004

Oliver, Gillian; Evans, Joanne; Reed, Barbara; Upward, Frank. Achieving the Right Balance: Recordkeeping Informatics, Part 1. iQ, November (2009). 18-21

Oliver, Gillian; Evans, Joanne; Reed, Barbara; Upward, Frank. Achieving the Right Balance: Recordkeeping Informatics, Part 2. iQ, February (2010). 42-44, 52

Truex, Duane; Olsson, Leif; Lindblad-Gidlund, Katarina; Sefyrin, Johanna; Larsson; Aron; Nilsson, Olof; Anderson, Karen; Borglund, Erik; Asproth, Viveca. Position Statement: Sustainable Information and Information Systems (SIIS) // Governance and Sustainability in Information Systems. Managing the Transfer and Diffusion of IT. IFIP WG 8.6 International Working Conference, Hamburg, Germany September 22-24, 2011, Proceedings. Nüttgens, N.; Gadatsch, A.; Kautz, K.; Schirmer, I., Blinn, N. (eds). Heidelberg: Springer (2011); 306-309

Upward, Frank; Reed, Barbara; Oliver, Gillian; Evans, Joanne. Recordkeeping Informatics: Refiguring a Discipline in Crisis With a Single Minded Approach. // Records Management Journal. Vol. 23 (2013) Iss 1; 37 - 50 http://dx.doi.org/10.1108/09565691311325013 